\section{Pengaruh servant leadership terhadap quality of work life pada karyawan generasi milenial}

\author{
Baiq Widya Ayu Ardiyanti ${ }^{1}$, Nida Hasanati ${ }^{1}$, dan Adhyatman Prabowo ${ }^{1}$
}

\begin{abstract}
Indonesia is entering a demographic surplus era where millennial generation employees occupy most of the existing work opportunities. When the organization pays attention to and fulfills the needs of millennial generation employees, this arguably will prosper the employees so that their quality of work life can be realized. Organizational support provided by leaders who try to prioritize common interests over personal interests or servant leadership is one of the things that creates employees' welfare because the employees' needs are met. The purpose of this study was to determine the effect of servant leadership on the quality of work life of millennial generation employees. This study used quantitative methods with the sampling technique employed is using total sampling with the number of subjects in this are 96 people at BUMN X in West Nusa Tenggara. The data collection method used the servant leadership scale of 18 items and the quality of work life scale of 34 items. Data analysis used the simple linear regression technique. The results showed that there was a significant positive effect of servant leadership on the quality of work life. Servant leadership has an effect of $48.6 \%$ on the quality of work life for millennial generation employees $(F=88.893, p=0.000,=0.486)$.
\end{abstract}

\title{
Keywords
}

Servant leadership, quality of work life, millennial generation employees.

\section{Pendahuluan}

Sumber daya manusia (SDM) merupakan unsur penggerak dalam mengarahkan, mengembangkan, serta mempertahankan kegiatan pada suatu organisasi atau perusahaan. Sedangkan karyawan merupakan kunci kesuksesan atau kegagalan sebuah organisasi. Seberapa baik sumber daya manusia yang dikelola akan menentukan keberhasilan dan kesuksesan perusahaan di masa mendatang (Purnaya, 2016).

Saat ini, Indonesia berada pada era bonus demografi, di mana jumlah populasi produktif atau yang sering disebut dengan generasi milenial memiliki jumlah yang lebih banyak dari generasi sebelumnya (Badan Pusat Statistik, 2017). Karyawan generasi milenial menempati $46 \%$ dari total keseluruhan lapangan pekerjaan pada tahun 2020 (Recruitufi, 2015).

Generasi milenial merupakan generasi masyarakat yang lahir pada tahun 1982-2000 (Strauss \& Howe, 1991). Generasi ini memiliki ciri menyukai keterbukaan, fleksibel, keinginan untuk bebas beraktivitas, dan mampu melihat permasalahan dari perspektif yang berbeda. Akan tetapi, generasi milenial sering memutuskan untuk berpindahpindah tempat kerja karena memiliki komitmen yang rendah terhadap organisasi (Suryaratri \& Abadi, 2018).

Fenomena yang ditemukan saat ini adalah tujuan individu bekerja tidak hanya untuk pemenuhan kebutuhan materi semata, namun juga memenuhi kebutuhan lain seperti kebutuhan untuk membentuk keterikatan sosial, dihargai oleh orang lain serta merasa kompeten dan mampu dalam kehidupan pekerjaan (Malvikawalia, 2016). Generasi milenial menganggap kurang berkesempatan dalam menunjukan kemampuan yang dimiliki dan kurangnya ketersediaan pengembangan karier, seperti program pelatihan maupun beasiswa. Padahal, pengembangan karier tersebut merupakan salah satu strategi dalam meningkatkan quality of work life (Avianti \& Kartika, 2017). Hurst \& Good (2009) menjelaskan bahwa generasi milenial berharap dapat berkesempatan untuk memberi kontribusi di perusahaan dan memperoleh hasil yang baik, mengembangkan kemampuannya, dan berani mengambil resiko.

Survei yang dilakukan oleh Jobstreet Employer ID (2016) menyatakan bahwa sebanyak $33.4 \%$ dari 27.000 karyawan generasi milenial merasa kurang memiliki quality of work life pada tempat kerja. Kurang quality of work life pada diri karyawan dapat menimbulkan perilaku menghindar. Perilaku ini terbagi menjadi empat, yaitu ketidakhadiran (absenteeism), perilaku kontra produktif, burnout, bahkan pindah kerja/ turnover (Priansa, 2014). Deloitte (2016) melakukan survei untuk melihat seberapa besar intensi karyawan generasi milenial meninggalkan perusahaannya. Diperkirakan pada tahun 2021, jumlah karyawan generasi milenial yang ingin meninggalkan perusahaan berjumlah 62\%. Survei yang dilakukan oleh Avianti \& Kartika (2017)

\footnotetext{
${ }^{1}$ Universitas Muhammadiyah Malang, Indonesia

Korespondensi:

Baiq Widya Ayu Ardiyanti, Fakultas Psikologi Universitas Muhammadiyah Malang

Email: Baiqwidyaayu@gmail.com
} 
juga menunjukan bahwa sebesar 52\% karyawan generasi milenial menganggap penting adanya pemenuhan faktorfaktor quality of work life.

Persaingan dalam dunia usaha yang semakin ketat menjadikan perusahaan sadar pentingnya melakukan pemenuhan quality of work life yang dimiliki oleh karyawan, karena itu mereka berusaha memberikan perhatian lebih (Allam \& Shaik, 2020). Organisasi perlu mengakui bahwa quality of work life dapat menjadi strategi sumber daya manusia untuk mempromosikan dan menjaga suasana kerja, sehingga karyawan dapat bekerja secara efektif dan mampu memenuhi tujuan organisasinya (Malvikawalia, 2016). Perusahaan pada dasarnya adalah suatu wahana dengan unsur manusia sebagai pelaksana kegiatan menjadi faktor penentu. "In order to achieve the good life people must work in good organizations" (Gavin \& Mason, 2004). Indonesia telah mengatur standar minimal pemenuhan quality of work life dengan dilaksanakannya UU Ketenagakerjaan Nomor 13 Tahun 2003, yang diantaranya mengatur tentang kesempatan dan perlakuan yang sama, pelatihan kerja, hubungan kerja, perlindungan, pengupahan, kesejahteraan karyawan, dan hubungan industrial (Departemen Tenaga Kerja dan Transmigrasi, 2003).

Perusahaan memiliki tanggung jawab untuk memelihara quality of work life dan membimbing karyawannya agar bersedia memberikan kontribusi secara optimal demi terwujudnya tujuan perusahaan (Pruijt, 2003). quality of work life adalah persepsi karyawan mengenai kesejahteraan, baik fisik maupun mental ketika bekerja (Cascio, 2010). Menurut Walton (1975), quality of work life merupakan persepsi karyawan terhadap pengalaman dan suasana pekerja pada tempat kerja dan respon efektif yang diberikan atas kebutuhan-kebutuhannya dalam mengembangkan mekanisme agar mampu terlibat sepenuhnya pada proses pembuatan keputusan yang menentukan kehidupan mereka di tempat kerja.

Pemenuhan quality of work life pada karyawan generasi milenial dapat memberikan pengaruh terhadap job satisfaction. Jabeen et al. (2018) menjelaskan bahwa quality of work life memiliki hubungan signifikan dan efek positif pada job satisfaction. Hasil yang sama ditunjukan pada penelitian Hardjanti et al. (2017) yang menunjukkan bahwa quality of work life berdampak positif pada psychological well-being yang dimiliki karyawan. Hal ini dikaitkan dengan perbaikan yang ditetapkan dapat mengarah pada peningkatan efektivitas organisasi dan kualitas kehidupan kerja yang berfokus pada staf.

quality of work life memiliki pengaruh terhadap kinerja karyawan. Hasmalawati (2018) menyatakan bahwa semakin tinggi quality of work life yang dimiliki karyawan, maka semakin tinggi pula kinerja pada tempat kerja. quality of work life menunjukan setiap kebijakan yang diputuskan perusahaan merupakan respon atas harapan dan keinginan karyawan guna meningkatkan kinerja. Pemenuhan quality of work life dalam suatu perusahaan juga dapat meningkatkan OCB yang dimiliki karyawan (Kurniawati, 2018). Timbulnya tindakan yang melampaui ketentuan minimum diharapkan oleh peran organisasi dan mempromosikan kesejahteraan rekan, kelompok, dan perusahaan.
Selain itu, quality of work life juga memiliki pengaruh terhadap keterikatan pegawai dan komitmen organisasi. Penelitian yang dilakukan oleh Sahni (2019) menjelaskan bahwa quality of work life memiliki hubungan signifikan dengan komitmen organisasi dan keterikatan karyawan. Hasil menunjukan bahwa terdapat kebutuhan untuk menciptakan pekerjaan yang lebih bermakna, sehingga dapat mendorong komitmen dan memberikan stimulus pribadi lebih besar pada pribadi karyawan.

Quality of work life juga memengaruhi perilaku burnout pada karyawan. Acar \& Erkan (2018) melakukan penelitian pada industri perhotelan Turki dan menemukan bahwa terdapat hubungan dan efek negatif signifikan antara quality of work life dan burnout. Hal ini sejalan dengan penelitian yang dilakukan Jabeen et al. (2018), quality of work life memiliki hubungan signifikan efek negatif pada turnover. Karyawan yang puas dengan gaji, promosi, keamanan kerja, dan partisipasi pengambilan keputusan cenderung memiliki intensi turnover rendah.

Berdasarkan pemaparan di atas, faktor-faktor yang dipengaruhi oleh quality of work life adalah komitmen organisasi, keterikatan pegawai, OCB, job satisfaction, turnover, psychological well- being, burnout, dan kinerja karyawan. Sistem penilaian terhadap quality of work life berhubungan dengan bagaimana organisasi menganggap investasi pada karyawan menjadi variabel penting dalam manajemen strategi organisasi (Elizur \& Shye, 1990). Organisasi yang mempertimbangkan quality of work life pada karyawan akan mendapatkan manfaat ketika memiliki banyak tenaga kerja yang berkomitmen sehingga berdampak pada produktivitas tenaga kerja yang lebih tinggi (Organ, 2017).

Faktor-faktor yang mempengaruhi quality of work life adalah job embeddedness. Penelitian Nafei (2015) menunjukkan bahwa job embeddedness mempengaruhi quality of work life. Job embeddedness yang tinggi akan mendorong karyawan bekerja secara kooperatif dalam tim. Selain itu Nafei (2016) juga melakukan penelitian bahwa organizational agility memengaruhi quality of work life. Organizational agility secara langsung memengaruhi dimensi quality of work life karyawan pada bank komersial Mesir.

Mahmoudi et al. (2019) menjelaskan bahwa quality of work life dipengaruhi oleh organizational happiness. Hasil penelitian menunjukan bahwa organizational happiness memiliki efek positif signifikan terhadap quality of work life pada karyawan Universitas Isfahan. Organizational happiness menunjukan karyawan harus aktif menghilangkan emosi negatif serta membentuk hubungan yang baik.

Faktor lain yang dapat memengaruhi quality of work life adalah kepemimpinan. Benjamin (2018) dan Kara et al. (2018) menyatakan terdapat pengaruh yang signifikan secara statistik antara gaya kepemimpinan dan quality of work life. Pemimpin membentuk strategi dalam organisasi meliputi pelaksanaan dan efektivitas. Pengelolaan sumber daya manusia yang baik akan mendorong karyawan menjadi lebih produktif dan menikmati pekerjaan yang menjadi tanggung jawabnya. Sejalan dengan penelitian yang dilakukan Merdiaty et al. (2019) yang menunjukan terdapat pengaruh langsung servant leadership terhadap quality of work life pada karyawan di perusahaan akuntansi. servant 
leadership berfungsi dalam proses menghargai sumber daya manusia dan berusaha untuk mempertahankannya.

Berdasarkan pemaparan di atas, maka faktor-faktor yang mempengaruhi quality of work life adalah job embeddedness, organizational agility, organizational happiness, leadership, dan servant leadership. Dari beberapa faktor yang mempengaruhi quality of work life, peneliti memilih untuk meneliti pengaruh servant leadership terhadap quality of work life karena fenomena-fenomena yang menjadi permasalahan dari kurangnya quality of work life pada karyawan secara tidak langsung mengungkapkan gap antara servant leadership dan quality of work life.

Adanya kekurangan dalam pemberian kesempatan bagi karyawan untuk menunjukan kemampuan yang dimiliki dan masa depan karier yang kurang jelas menyebabkan karyawan generasi milenial merasa kurang berkesempatan untuk mengembangkan kemampuan dan diri. Salah satu faktor krusial perusahaan dalam pengembangan kualitas sumber daya manusia adalah kepemimpinan. Peran pemimpin dalam suatu organisasi tidak kalah penting dengan karyawan, karena pemimpin sangat menentukan kelangsungan hidup serta perkembangan suatu perusahaan (Ancok, 2012).

Hal yang menjadi perhatian dalam pemenuhan quality of work life karyawan generasi milenial adalah kesempatan pengembangan karir, insentif, dan gaya kepemimpinan (Avianti \& Kartika, 2017). Kepemimpinan merupakan seseorang yang menentukan jalannya suatu organisasi dengan membentuk strategi kelembagaan berupa pelaksanaan dan efektivitas serta memiliki hubungan sebab akibat dengan kesuksesan organisasi, menentukan budaya, nilai, perubahan, toleransi, dan motivasi kerja karyawan (Benjamin, 2018). Servant leadership dipilih karena jenis kepemimpinan ini berfokus pada membantu individu untuk mengembangkan dirinya. Hal ini dilakukan dengan memberikan kesempatan karyawan untuk terlibat agar berhasil dalam pekerjaan maupun kehidupan dan memperlakukan individu dengan lebih manusiawi, bukan berdasarkan pada posisi dan kekuasaan yang dimiliki (Chughtai, 2016). Indonesia memiliki budaya kolektif yang cenderung setia dan hormat pada seseorang atau kelompok dengan menunjukan perhatian dan kepedulian kepada mereka (Hofstede, 2016). Inilah yang menyebabkan masyarakat Indonesia menyukai pemimpin yang memikirkan kepentingan pengikutnya.

Nawawi (2012) mengungkapkan bahwa ketika melihat dari segi psikologis, manusia hanya melakukan suatu kegiatan yang menyenangkan untuk dilakukan sehingga berpengaruh terhadap kepuasan yang dirasakan. Pada dasarnya, gaya kepemimpinan servant leadership memberikan pemuasan kepada kebutuhan karyawan dan dapat meningkatkan kepuasan kerja dalam organisasi (Mayer et al., 2008). Servant leadership menempatkan diri sebagai pelayan dalam organisasi, berusaha menumbuhkan sumber daya, keuangan, dan hal lain yang telah menjadi tanggung jawab yang harus diemban (Dierendonck \& Nuijen, 2011). Pemimpin yang menerapkan servant leader tersebut akan mampu memberikan pengaruh positif terkait hubungan mereka dengan para karyawan dengan tidak menimbulkan rasa segan ataupun ketakutan yang berlebihan (Putri, 2018). Perilaku yang diterapkan oleh servant leadership adalah mempersuasi karyawan dengan hal positif, mendorong, dan membimbing karyawan agar lebih berkembang dengan mendengarkan setiap aspirasi yang disampaikan, menampung semua pendapat yang diberikan, dan mampu membuat keputusan dengan bijaksana (Lantu et al., 2007).

Servant leadership dapat meningkatkan kesejahteraan karyawan dengan mendorong serta melibatkan karyawan mengambil inisiatif dan menentukan cara kerja. Perusahaan yang memperhatikan kesejahteraan karyawan dan memberikan kesempatan untuk tumbuh dapat membuat mereka terlibat dan efektif saat bekerja (Harju et al., 2018). Ketika kesejahteraan karyawan menjadi prioritas, mereka akan terlibat secara efektif saat bekerja sehingga dapat mencapai quality of work life yang baik di tempat kerjanya. Perusahaan yang memberikan respon efektif pada kebutuhan-kebutuhan karyawan dalam pengembangan mekanisme untuk turut terlibat dan menjadi bagian dari perusahaan akan dapat mewujudkan quality of work life karyawan (Avianti \& Kartika, 2017). Karyawan generasi milenial tidak menginginkan atasan yang memiliki pola sebagai pengontrol dan suka memerintah. Servant leadership membentuk suasana kerja yang saling menghormati dan menginginkan kerja sama tim dalam penyelesaian pekerjaan maupun masalah.

Perbedaan penelitian yang akan dilakukan dengan penelitian terdahulu yaitu terletak pada subjek. Penelitian terdahulu yang telah dilakukan Merdiaty et al. (2019) menggunakan subjek karyawan pada salah satu perusahaan akuntansi, sedangkan peneliti menggunakan subjek generasi milenial. Pada tahun 2020, Indonesia memasuki era bonus demografi di mana generasi milenial akan memiliki jumlah lebih banyak dari generasi sebelumnya dan berada pada usia produktif. Karyawan generasi milenial menjadi tulang punggung perekonomian bangsa (Badan Pusat Statistik, 2018). Karyawan generasi milenial akan menempati $46 \%$ dari total keseluruhan lapangan pekerjaan pada tahun 2020 (Recruitufi, 2015).

Pengoptimalan kontribusi yang dimiliki karyawan generasi milenial akan meningkatkan kinerja dan produktivitas perusahaan. Perhatian dan respon terhadap kebutuhan yang diberikan oleh pemimpin kepada karyawan akan membentuk persepsi kesejahteraan karena terpenuhinya kebutuhan fisik dan mental pada tempat kerja. Servant leadership dan quality of work life khususnya pada karyawan generasi milenial perlu diteliti karena dapat berdampak pada persepsi dan kinerja yang ditunjukan. Penelitian ini bertujuan untuk mengetahui pengaruh servant leadership terhadap quality of work life pada karyawan generasi milenial sehingga pemimpin maupun perusahaan mengetahui bagaimana mengukur quality of work life untuk meningkatkan produktivitas di tempat kerja.

Berdasarkan uraian latar belakang di atas, manfaat teoritis dari penelitian ini adalah dapat memberikan wawasan serta sumbangan referensi bagi pengembangan ilmu pengetahuan dan teori khususnya psikologi industri dan organisasi. Selain itu, penelitian ini diharapkan pula dapat memberikan manfaat praktis bagi organisasi dan menjadi masukan bagi perusahaan dalam pengembangan sumber daya manusia sehingga mampu memaksimalkan performa serta efektivitas organisasi. 
Tabel 1. Deskripsi Demografis Subjek Penelitian ( $\mathrm{N}=96)$

\begin{tabular}{lll}
\hline Kategori & Frekuensi & Persentase \\
\hline Jenis Kelamin & & \\
Laki-laki & 66 & $68.8 \%$ \\
$\quad$ Perempuan & 30 & $31.3 \%$ \\
Pendidikan Terakhir & & \\
$\quad$ Sarjana & 49 & $51 \%$ \\
Diploma & 11 & $11.5 \%$ \\
SLTA/Setara & 36 & $37.5 \%$ \\
Usia & & \\
$20-25$ & 3 & $3.1 \%$ \\
$26-30$ & 32 & $33.3 \%$ \\
$31-35$ & 44 & $45.8 \%$ \\
$36-39$ & 17 & $17.7 \%$ \\
\hline
\end{tabular}

\section{Metode}

Penelitian ini merupakan penelitian kuantitatif noneksperimental dengan pendekatan asosiatif kausal. Penelitian kuantitatif adalah suatu cara yang digunakan dengan melibatkan data berupa angka dan program statistik untuk menjawab masalah dalam penelitian (Creswell, 2014). Metode non-eksperimental adalah penelitian yang dilakukan pada subjek sesuai dengan keadaan sebenarnya tanpa ada manipulasi atau intervensi dari peneliti. Pendekatan asosiatif kausal bertujuan untuk mengetahui sebab akibat dan apakah ada pengaruh atau hubungan antara dua variabel, yaitu variabel bebas dan variabel terikat. Penelitian ini menggunakan skala likert sesuai dengan variabel yang akan diukur pada subjek penelitian.

\section{Subjek Penelitian}

Subjek dalam penelitian ini adalah karyawan pada salah satu perusahaan BUMN X di Nusa Tenggara Barat. Populasi adalah keseluruhan individu yang yang dimaksudkan untuk diteliti (Winarsunu, 2017). Populasi dalam penelitian ini merupakan karyawan generasi milenial sebanyak 96 orang pada salah satu perusahaan BUMN X di Nusa Tenggara Barat, berusia 20 hingga 39 tahun (Strauss \& Howe, 1991). Selanjutnya, melihat jumlah subjek atau populasi yang kurang dari 100, maka peneliti berpedoman pada pendapat Arikunto (2006) yang menjelaskan apabila subjek populasi berjumlah kurang dari 100, maka lebih baik semua subjek diambil, sehingga yang digunakan sebagai subjek penelitian adalah keseluruhan total populasi. Penelitian yang menggunakan seluruh anggota populasi dijadikan sampel atau subjek dalam penelitian, maka dapat disebut sampel jenuh atau sensus. Berdasarkan data yang dipaparkan pada tabel 1, subjek dalam penelitian ini merupakan karyawan generasi milenial yang sebagian besar berada dalam rentang usia 31-35 tahun berjenis kelamin laki-laki dengan pendidikan terakhir yaitu sarjana.

Tabel 1 menjelaskan subjek dalam tiga kategori, yaitu jenis kelamin, jurusan dan usia. Berdasarkan jenis kelamin, mayoritas dalam penelitian ini adalah perempuan dengan prosentase sebesar $70 \%$ dan jurusan yang mendominasi yaitu Saintek dengan prosentase 58\%. Apabila dilihat dari usia, mayoritas partisipan berusia 22 tahun sebanyak $35 \%$.

\section{Variabel dan Instrumen Penelitian.}

Penelitian ini menggunakan dua variable, yakni variabel bebas (X) dan variabel terikat (Y) dengan servant leadership sebagai variabel bebas (X) dan quality of work life sebagai variabel (Y). servant leadership adalah persepsi karyawan mengenai tipe atau gaya kepemimpinan yang dimiliki oleh kepala bagian mencakup pendekatan kepemimpinan yang menggunakan perasaan tulus untuk melayani serta menempatkan kepentingan bersama di atas kepentingan pribadi, membentuk hubungan yang baik antar rekan kerja, memiliki gambaran akan masa depan dengan memberikan motivasi karyawan, memberi kesempatan sumber daya untuk berkembang sendiri, percaya akan kekuatan atau kemampuan yang dimiliki karyawan, secara efektif mendengarkan menyebabkan karyawan merasa dihargai, dan membentuk suasana kerja yang saling menghormati. Penelitian ini menggunakan skala milik Dierendonck et al. (2017) yang diadaptasi dari instrumen milik Dierendonck \& Nuijen (2011). Instrumen yang digunakan terdiri dari lima komponen yaitu empowerment, humility, standing back, stewardship, dan authenticity. Instrumen skala yang digunakan ini hanya menggunakan lima dari delapan dimensi yang dijelaskan oleh Dierendonck \& Nuijen (2011), dikarenakan telah melalui uji lintas budaya pada delapan negara di Eropa dengan perbedaan karakteristik, bahasa, budaya, kebiasaan, dan sejarah serta mencerminkan dimensi inti servant leadership dengan model faktor yang stabil dan menjadi dasar di berbagai negara. Skala ini terdiri atas 18 item.

Quality of work life adalah persepsi karyawan mengenai kesejahteraan secara mental maupun fisik, meliputi pengalaman dan suasana pada tempat kerja dimana karyawan memiliki keseimbangan kehidupan, secara relatif merasa puas mendapat kesempatan yang sama untuk tumbuh dan berkembang layaknya manusia, dan memberikan respon efektif terhadap kebutuhan- kebutuhan karyawan. quality of work life atau kualitas kehidupan kerja pada penelitian ini didasarkan pada delapan komponen, yaitu kompensasi yang mencakup dan adil, kondisi kerja yang aman dan sehat, kesempatan untuk mengembangkan dan menggunakan kemampuan, peluang untuk pertumbuhan dan mendapatkan jaminan, rasa memiliki, hak-hak karyawan, pekerja dan ruang hidup secara keseluruhan, dan tanggung jawab sosial organisasi. Instrumen penelitian menggunakan skala quality of work life berdasarkan teori Walton (1975) yang dikembangkan oleh Timossi et al. (2008) sebanyak 35 item.

Kedua alat ukur dalam penelitian ini menggunakan skala likert. Teknik yang dipakai dalam proses pengambilan data pada kedua skala menggunakan skala likert, di mana skala likert adalah skala yang digunakan untuk mengukur sikap, persepsi, pendapat, individu, atau sekelompok orang terhadap suatu fenomena sosial (Sugiyono, 2012). Kedua skala terdiri atas item yang bersifat positif (favourable). Skala servant leadership memiliki lima pilihan jawaban yakni, sangat tidak setuju (STS), tidak setuju (TS), ragu-ragu (R), setuju (S), dan sangat setuju (SS). Skala quality of work life terdiri atas lima pilihan jawaban dengan bentuk skala likert yaitu berupa sangat tidak puas (STP), tidak puas (TP), netral $(\mathrm{N})$, puas $(\mathrm{P})$, dan sangat puas $(\mathrm{SP})$.

Uji validitas dan reliabilitas alat ukur servant leadership dan quality of work life dilakukan dengan uji coba 
pada subjek sebanyak 100 karyawan generasi milenial menggunakan bantuan google form. Hasil uji validitas alat ukur servant leadership menghasilkan 18 item valid dengan indeks validitas sebesar 0.299-0.671. Sedangkan hasil uji validitas alat ukur quality of work life dari 35 item dengan 1 item yang tidak valid. Maka tersisa 34 item valid dengan indeks validitas $0.252-0.660$. Nilai dikatakan valid jika $R$ hitung $>\mathrm{R}$ tabel, sedangkan $\mathrm{R}$ tabel pada penelitian ini adalah 0,1966. Hasil ini menunjukan bahwa kedua alat ukur valid (Sugiyono, 2012).

Dari uji reliabilitas pada alat ukur servant leadership, didapatkan koefisien alpha cronbach sebesar 0,898 . Sedangkan hasil uji reliabilitas alat ukur quality of work life memiliki koefisien alpha cronbach sebesar 0,903. Hal ini berarti bahwa alat ukur servant leadership dan quality of work life reliabel, karena nilai Cronbach's Alpha >0,6. Reliabilitas adalah indeks yang menunjukan sejauh mana alat ukur yang digunakan dapat dipercaya dengan menunjukan hasil tetap konsisten bila dilakukan pada penelitian lain (Sugiyono, 2012). Oleh karena itu, kedua alat ukur dapat digunakan karena sudah menunjukan hasil yang valid dan reliabel untuk digunakan dalam penelitian.

\section{Prosedur dan Analisis Data}

Secara umum, terdapat tiga prosedur atau langkah utama pada penelitian ini, yaitu persiapan, pelaksanaan, dan analisis data. Tahap persiapan dimulai dengan mengidentifikasikan permasalahan serta batasan penelitian sesuai dengan tujuan dengan menguraikan permasalahan yang ada di lapangan. Menentukan variabel diiringi dengan memberikan penjelasan tiap variabel menggunakan kajian teoritik, kemudian menentukan hipotesis penelitian. Proses dilanjutkan dengan adaptasi alat ukur pada skala jurnal internasional dengan mempertimbangkan aspek maupun dimensi yang sesuai dengan variabel agar memperoleh informasi yang sesuai dan terpercaya Selanjutnya, sebelum melakukan proses pengambilan data, terlebih dahulu dilakukan try out atau uji coba alat ukur pada karyawan. Kriteria karyawan adalah generasi milenial yang lahir pada tahun 1982-2000 atau berusia antara 20-38 tahun. Alasan dilakukan try out atau uji coba yaitu untuk mengetahui jumlah item yang valid dan reliabel pada skala yang akan digunakan, sesuai dengan aspek variabel yang akan diteliti. Proses selanjutnya adalah melakukan analisis data untuk mengetahui item pada skala yang valid dan reliabel menggunakan Statistical Package for Social Science (SPSS).

Tahap pelaksanaan dilakukan dengan pengambilan data menggunakan skala yang telah diuji coba serta dinyatakan valid dan reliabel. Proses pengambilan data dilakukan kepada karyawan di suatu perusahaan yang memenuhi kriteria yang telah ditentukan terlebih dahulu. Penelitian ini menggunakan dua jenis skala sesuai dengan variabel yang digunakan, yaitu skala servant leadership dan quality of work life.

Tahap terakhir adalah analisis data. Pada tahap ini, dilakukan pengolahan data dari dua skala yang telah disebarkan. Penelitian ini menggunakan alat bantu perhitungan berupa program statistik SPSS for Windows versi 25. Analisis regresi merupakan analisis yang bertujuan untuk mengetahui pengaruh antara suatu variabel terhadap variabel lain. Pada suatu penelitian, hanya terdapat satu variabel independen dan satu variabel dependen, yang disebut sebagai persamaan regresi linear sederhana. Teknik statistik regresi linier sederhana berdasarkan pada hubungan kausal ataupun fungsional satu variabel independen (variabel bebas) dengan satu variabel dependen (variabel terikat) (Sugiyono, 2012). Hasil kedua skala yang telah disebarkan dianalisis dengan teknik regresi linier sederhana. Teknik regresi linier sederhana digunakan untuk mengetahui pengaruh variabel $\mathrm{x}$ (servant leadership) dan variabel y (quality of work life).

\section{Hasil}

Penelitian telah dilakukan dengan penyebaran skala berbasis paper base kepada karyawan generasi milenial sebanyak 96 orang yang bekerja pada perusahaan karyawan BUMN $X$ di Nusa Tenggara. Hasil pengolahan data klasifikasi kategorisasi servant leadership dan quality of work life dibagi menjadi dua kategori, yaitu rendah dan tinggi. Adapun rincian klasifikasi kategorisasi akan dipaparkan pada Tabel 2.

Dari hasil yang ditunjukan pada tabel 2, diketahui variabel servant leadership didominasi oleh karyawan yang berada pada kategori tinggi berjumlah 62 subjek dengan persentase sebesar $64.6 \%$. Variabel quality of work life yang dimiliki karyawan juga berkategori tinggi sejumlah 53 subjek dengan persentase $55.2 \%$. Maka diketahui bahwa rata-rata servant leadership dan quality of work life karyawan milenial BUMN $\mathrm{X}$ di NTB berada pada kategori tinggi.

\section{Uji Normalitas Variabel Servant Leadership dan quality of work life}

Berdasarkan uji normalitas Kolmogorov-smirnov, data dapat dikatakan normal jika nilai signifikansi di atas 0.05. Hasil uji normalitas yang telah dilakukan pada dua variabel yaitu servant leadership dan quality of work life didapatkan hasil yaitu 0.200 dan 0.136 . Sehingga data dapat dikatakan normal karena nilai signifikansi $>0.05$.

Hasil uji regresi sederhana yang telah dilakukan menunjukkan koefisien regresi (B) sebesar 0.844. Angka tersebut menunjukan nilai positif yang dapat diartikan adanya korelasi searah servant leadership terhadap quality of work life. Selanjutnya, diketahui nilai signifikansi sebesar 0.000, karena $\mathrm{p}<0.05$, sehingga memberikan kesimpulan bahwa terdapat pengaruh positif yang signifikan antara servant leadership dan quality of work life. Nilai $\mathrm{F}$ melihat bagaimana variabel bebas berpengaruh terhadap variabel terikat menunjukan angka sebesar 88.893, yang berarti linier dengan nilai koefisien determinasi ( $R$ Square) sebesar 0.486. Maka dapat disimpulkan adanya pengaruh variabel servant leadership (X) terhadap variabel quality of work life (Y), dengan pengaruh sebesar $48.6 \%$. Sisanya sebesar $51.4 \%$ dipengaruhi oleh faktor lain yang tidak terdapat dalam penelitian ini.

Tabel 2. Kategorisasi Servant Leadership dan quality of work life

\begin{tabular}{llll}
\hline Variabel & Interval & Frekuensi & Persentase \\
\hline Servant Leadership & $63-74$ & 34 & $35.4 \%$ \\
& $75-85$ & 62 & $64.6 \%$ \\
quality of work life & $75-85$ & 62 & $64.6 \%$ \\
& $75-85$ & 62 & $64.6 \%$ \\
\hline
\end{tabular}




\section{Diskusi}

Hasil dari penelitian ini didukung dengan penelitian yang dilakukan Sumathi \& Velmurugan (2017) bahwa quality of work life dipengaruhi oleh kepemimpinan, struktur organisasi, tersedia peluang pertumbuhan pribadi, lingkungan kerja, sistem pemberian upah yang adil, dan keseimbangan kehidupan kerja. Hal ini sejalan dengan penelitian yang dilakukan pada karyawan perusahaan akuntansi, bahwa terdapat pengaruh langsung antara servant leadership terhadap quality of work life (Merdiaty et al., 2019). Pemimpin dengan servant leadership menghargai sumber daya manusia yang dimiliki dan berusaha untuk mempertahankan.

Penelitian ini bertujuan untuk mengetahui pengaruh servant leadership terhadap quality of work life pada karyawan generasi milenial. Hasil yang didapatkan dari analisis regresi linier sederhana adalah servant leadership berpengaruh sebesar 48,6\% terhadap quality of work life. Hal ini menunjukan bahwa hipotesis dalam penelitian ini diterima, yaitu adanya pengaruh positif yang signifikan antara servant leadership terhadap quality of work life pada karyawan generasi milenial. Terbuktinya hipotesis menjelaskan bahwa servant leadership menjadi salah satu faktor yang memengaruhi quality of work life.

Pemimpin memiliki peran vital dalam menjalankan pekerjaan serta menjadi acuan dan contoh bagi bawahan. Kepemimpinan merupakan seseorang yang menentukan jalannya suatu organisasi dengan membentuk strategi kelembagaan berupa pelaksanaan dan efektifitas serta memiliki hubungan sebab akibat dengan kesuksesan organisasi, menentukan budaya, nilai, perubahan, toleransi dan motivasi kerja karyawan (Benjamin, 2018). servant leadership menempatkan diri sebagai pelayan dalam organisasi, berusaha menumbuhkan sumber daya, keuangan dan hal lain yang telah menjadi tanggung jawab yang harus diemban (Dierendonck \& Nuijen, 2011).

Pemimpin harus memberikan kesempatan bagi karyawan mencapai kesuksesan dan berkomitmen untuk membantu memberikan akses untuk meraih kesuksesan. Pemimpin menghargai karyawan akan membuat karyawan bekerja dengan maksimal dan mendapatkan kepercayaan anggota organisasi. servant leadership adalah pendekatan kepemimpinan yang menggunakan perasaan tulus pemimpin untuk melayani meletakan kepentingan karyawan di atas kepentingan pemimpin, dimana melibatkan dan memberdayakan karyawan untuk tumbuh dan menggunakan kemampuan yang dimiliki (Greenleaf, 2002). Pemimpin yang menerapkan servant leadership tersebut akan mampu memberikan pengaruh positif terkait hubungan mereka dengan para karyawan dengan tidak menimbulkan rasa segan ataupun ketakutan yang berlebihan terhadap pemimpin mereka (Putri, 2018).

Saat kesejahteraan karyawan menjadi perhatian serta pemberian kesempatan untuk tumbuh, menyebabkan mereka terlibat dan efektif saat bekerja (Harju et al., 2018). Hal ini akan membentuk persepsi karyawan mengenai kesejahteraan fisik maupun mental terkait dengan suasana dan pengalaman di tempat kerja dan merasa puas mendapatkan kesempatan berkembang dengan pemenuhan kebutuhan karyawan di tempat kerja. Sehingga akan terbentuk quality of work life yaitu sebuah konstruk yang komprehensif mengenai persepsi karyawan terhadap pengalaman dan suasana kerja yang bermanfaat dan memuaskan pada tempat kerja serta seberapa efektif respon yang diberikan organisasi pada kebutuhankebutuhan karyawan sehingga terlibat sepenuhnya pada proses pembuatan keputusan yang merancang bagaimana kehidupan mereka di tempat kerja (Walton, 1975).

Generasi milenial berharap mendapatkan kesempatan berkontribusi di perusahaan dan memperoleh hasil yang baik, mengembangkan kemampuannya dan berani mengambil resiko (Hurst \& Good, 2009). Karyawan generasi milenial tidak menginginkan atasan yang memiliki pola sebagai pengontrol dan suka memerintah. Sebaliknya mereka menginginkan untuk mendapatkan kesempatan untuk terlibat dan menyampaikan ide serta berkontribusi pada pekerjaan sehingga dapat mengembangkan kemampuan (Suryaratri \& Abadi, 2018). Gaya kepemimpinan merupakan salah satu yang menjadi perhatian penting bagi pemenuhan quality of work life pada karyawan generasi milenial (Avianti \& Kartika, 2017). servant leadership membentuk suasana kerja yang saling menghormati dan menginginkan kerja sama tim dalam penyelesaian pekerjaan maupun masalah (Chughtai, 2016). Suasana dan kondisi kerja yang nyaman dan aman memungkinkan adanya interaksi serta keterlibatan dalam kerjasama tim dalam penyelesaian konflik maupun pengambilan keputusan.

Indonesia memiliki budaya kolektif yaitu cenderung setia dan hormat pada seseorang atau kelompok yang menunjukan perhatian dan kepedulian kepada mereka (Hofstede, 2016). Sejalan dengan hasil penelitian yang dilakukan oleh (Liman et al., 2017) dimana hal yang berpengaruh paling tinggi bagi job performance karyawan adalah pemimpin yang meletakan kepentingan bersama terlebih dahulu diatas kepentingan bersama. Hasil dari penelitian ini menunjukan bahwa masyarakat Indonesia cenderung menyukai pemimpin yang menempatkan kepentingan pengikut diatas kepentingan pemimpin itu sendiri.

Dari 96 karyawan generasi milenial, terdapat 53 subjek pada kategori quality of work life yang tinggi. Berdasarkan hasil dari data demografis subjek, didapatkan bahwa 44 subjek berada pada rentang usia 31-35 dan 37 subjek telah bekerja selama 7-9 tahun. Sesuai dengan hasil penelitian yang dilakukan Ryff \& Keyes (1995), usia memiliki pengaruh positif terhadap quality of work life karyawan. Penelitian Gupta \& Gupta (2013) juga menunjukkan bahwa karyawan yang berusia lebih tua memiliki tingkat quality of work life yang lebih tinggi daripada karyawan yang lebih muda. Hal ini dikarenakan karyawan yang lebih tua sudah memiliki banyak pengalaman yang dari banyaknya waktu yang dihabiskan dengan perusahaan, berupa wawasan, kompetensi, serta peningkatan dalam segi karir, baik dalam penyesuaian dengan lingkungan atau merasa senang dengan kehidupannya (Huppert, 2009). Pendidikan dominan yang ditempuh subjek adalah sarjana dengan jumlah 49 subjek. Tingkat pendidikan dapat mempengaruhi psikologi manusia dalam menerima pemberdayaan.

Berdasarkan hasil penelitian, terdapat 64,6\% atau 62 karyawan generasi milenial yang memilih servant leadership kategori tinggi. Hal ini dapat dikatakan bahwa pemimpin lebih memprioritaskan pada kebutuhan orang lain di atas kebutuhan pribadi, sehingga menimbulkan hubungan yang 
baik dengan pekerja. Pemimpin yang memberikan respon efektif pada kebutuhan karyawan untuk terlibat dan menjadi bagian dari perusahaan dapat mewujudkan quality of work life (wahyuningsih, 2016).

Tujuan individu bekerja tidak hanya untuk pemenuhan kebutuhan materi semata, namun juga memenuhi kebutuhan lain seperti membentuk keterikatan sosial, dihargai oleh orang lain, serta merasa kompeten dan mampu dalam kehidupan pekerjaan (Malvikawalia, 2016). Ketika quality of work life telah terpenuhi, akan muncul perilaku yang menguntungkan organisasi, antara lain organizational citizenship behavior, kesehatan mental dan fisik, kinerja, berkurang perilaku menghindar (withdrawal behavior), serta kepuasan kerja (Priansa, 2014). Banyaknya keuntungan yang dimiliki ketika karyawan mencapai quality of work life membuat perusahaan-perusahaan sadar dan berusaha memberikan perhatian lebih (Allam \& Shaik, 2020).

Karyawan akan bekerja dengan maksimal sesuai tugas yang diberikan oleh perusahaan ketika kebutuhan yang sesuai persepsi terpenuhi. Sesuai dengan pendapat Vygotsky tentang teori belajar kognitif, kemampuan yang muncul dari hubungan sosial dan kultur muncul dari harapan yang terbentuk sesuai dengan respon yang diberikan (Santrock, 2017). Proses belajar ini melibatkan perubahan pada persepsi dan perilaku. Ketika karyawan mendapatkan perlakuan servant leadership yang mementingkan kepentingan pengikut di atas pribadi, maka ia akan membentuk persepsi dan perilaku mengenai pemenuhan quality of work life pada tempat kerja (Fieldman, 2012). Oleh karena itu, penting bagi pihak perusahaan untuk melakukan pengkajian mengenai kebutuhan pekerja, sehingga akan timbul perilaku yang meningkatkan quality of work life karyawan demi tercapainya tujuan dan harapan perusahaan.

Penelitian ini memiliki beberapa kelemahan, yaitu proses tryout dilakukan secara online di mana peneliti tidak dapat mengontrol langsung pengisian instrumen. Selain itu, proses pengambilan data populasi hanya menggunakan karyawan atau pekerja dari satu perusahaan. Bisa saja servant leadership dan quality of work life pada karyawan generasi milenial di perusahan lain mendapatkan hasil berbeda. Adapun kelebihan dari penelitian ini adalah masih minim penelitian di Indonesia mengenai quality of work life pada karyawan generasi milenial.

\section{Kesimpulan}

Berdasarkan hasil penelitian yang telah dilakukan, dapat disimpulkan bahwa hipotesis dalam penelitian ini diterima, yaitu terdapat pengaruh positif yang signifikan antara servant leadership terhadap quality of work life pada karyawan generasi milenial. servant leadership berpengaruh sebesar $48.6 \%$ terhadap quality of work life. Hasil tersebut menunjukan bahwa servant leadership merupakan salah satu faktor yang memengaruhi quality of work life.

Karyawan merupakan sumber daya yang memiliki peran penting dalam tercapainya tujuan organisasi sehingga diperlukan perhatian lebih. Perusahaan perlu mengambil tindakan dalam upaya pemenuhan, peningkatan, dan menjaga quality of work life pada karyawan. Salah satu faktor pemenuhan quality of work life yaitu dengan servant leadership atau pemimpin pelayanan yang mementingkan kepentingan orang lain di atas kepentingan pribadi. Diharapkan semakin banyak organisasi memberikan pengetahuan baru mengenai servant leadership yang diterapkan oleh para pemimpin agar karyawan mampu mencapai kesejahteraan yang akan berdampak positif bagi kinerja. Bagi karyawan, diharapkan mampu menerima dan menyikapi perubahan dan hal yang tidak sesuai rencana yang terjadi sebagai sebuah tantangan, bukan menjadikan masalah sehingga tetap dapat menunjukan kinerja yang lebih produktif. Bagi peneliti selanjutnya yang tertarik meneliti variabel servant leadership dan quality of work life dapat menambahkan variabel lain untuk meningkatkan pengaruh dari variabel yang digunakan dalam penelitian ini. Selain itu, peneliti selanjutnya juga dapat mengambil jumlah subjek lebih banyak dan luas dari beberapa perusahaan sehingga dapat membuktikan lebih dalam lagi pengaruh kedua variabel tetap sama pada beberapa perusahaan yang berbeda.

\section{Referensi}

Acar, A \& Erkan, M. (2018). The effects of quality of work life on burnout syndrome: a study on hospitality industry. Journal of Tourismology, 4(1), 35-53. doi 10.26650/jot.2018.4.1.0006

Allam, Z \& Shaik, A. R. (2020). A study on quality of work life amongst employess working in the Kingdom of Saudi Arabia. Management Science Letters, 10(6), 1287- 1294. doi: 10.5267/j.msl.2019.11.029

Ancok, D. (2012). Psikologi kepemimpinan dan inovasi. Jakarta: Penerbit Erlangga.

Arikunto, S. (2006). Prosedur penelitian suatu pendekatan praktik. Jakarta: PT. Rineka Cipta.

Avianti, D A \& Kartika, L. (2017). Analisis quality of work life pada generasi $\mathrm{x}$ dan $\mathrm{y}$ alumni fakultas ekonomi dan manajemen ipb. Jurnal Riset Manajemen dan Bisnis Fakultas Ekonomi UNIAT, 2(2), 95-106. doi: https://doi.org/10.36226/jrmb.v2i2.40

Badan Pusat Statistik. (2017). Proyeksi penduduk Indonesia 2010-2035. Diakses dari http: www.demografi.bps.go.id. pada tanggal 5 Februari 2020.

Badan Pusat Statistik. (2018). Statistik gender tematik: Profil generasi milenial indonesia. Jakarta: Kementerian Pemberdayaan Perempuan dan Perlindungan Anak.

Benjamin, O A. (2018). Impact of organisational culture and leadership style on quality of work- life among employees in nigera. African Journal for The Psychological Study of Social Issues, 18(1), 109-121. doi:10.4314/AJPSSI.V18I1

Cascio, W. F. (2010). Managing human resources: Productivity, quality of work life, profits (eight edition). New York: McGrawHill

Chughtai, A A. (2016). Servant leadership and follower outcomes: mediating effects of organizational identification and psychological safety. The Journal of Psychology Interdisciplinary and Applied, 150(7), 1-15. doi 10.1080/0223980.2016.1170657

Creswell, J W. (2014). Penelitian kualitatif \& desain riset. Yogyakarta: Pustaka Pelajar.

Deloitte. (2016). The 2016 deloitte millennial: Survey winning over the next generation of leaders. Diakses dari http://www.deloitte.com/ pada Maret 2020.

Departemen Tenaga Kerja dan Transmigrasi. (2003). Undang-undang no. 13 tahun 2003. Diakses dari 
http://www.depnakertrans.go.id/perundangan.html,1,69,1.

Dierendonck, D. V., \& Nuijen, I. (2011). The servant leadership survey: development and validation of multidimensional measure. Journal of Business and Psychology, 26, 249-267. doi: 10.1007/s10869-010-9194-1

Dierendonck, D. V., Sousa, M., Gunnarsdóttir, S., Bobbio, A., Hakanen, J., Verdorfer, A. P., Duyan, A. C., \& Carvajal, R R. (2017). The cross-cultural invariance of the servant leadership survey: A comparative study across eight countries. Administrative Science, 7(2), 8. doi https://doi.org/10.3390/admsci7020008

Elizur, D., \& Shye, S. (1990). quality of work life and its relation to quality of life. Applied Psychology: An International Review. 39(3) 275-291. https://doi.org/10.1111/j.14640597.1990.tb01054.x

Fieldman, R.S. (2012). Pengantar Psikologi: Understanding Psychology edisi 10. Jakarta: Salemba Humanika.

Gavin, J.H., \& Mason, R.O. (2004). The virtuous organization: The value of happiness in the workplace. Organizational Dynamics, 33(4), 379-392. doi: https://doi.org/10.1016/j.orgdyn.2004.09.005

Greenleaf, R. K. (2002). Servant-Leadership: A Journey into the nature of legimate power and greatness (L.C. Spears, Ed) (Anniversary Edition). New York: Paulist Press.

Gupta, B., \& Gupta, S. (2013). A study impact of quality of work life on organizational commitment in manufacturing sector. International Journal of Research in Management Science and Technology, 1(3), 27-32.

Hardjanti, I.W., Noermijati, \& Dewanto, A. (2017). Influence of quality of work life toward psychological well-being and turnover intension on nurses and midwives in hospital Kesmas: National Public Health Journal, 12(1), 7-14. doi: http://dx.doi.org/10.21109/kesmas.v12i1.1144

Harju, L K., Schaufeli, W B \& Hakanen, H J. (2018). A multilevel study on servant leadership, job boredom and job crafting. Journal of Managerial Psychology, 33(1), 2-14. doi: 10.1108/JMP-08-2016-0237

Hasmalawati, N. (2018). Pengaruh kualitas kehidupan kerja dan motivasi kerja terhadap kinerja karyawan. Jurnal Psikolog Ilmiah, 10(1), 26-35. doi: 10.15294/intuisi.v10i1.17383

Hofstede, G. (2016). Geert-Hofstede what about Indonesia? Retrieved from Geert-Hodtede. Diakses dari https://geerthofstede.com/indonesiahtml. Retrieved 20-3-2020.

Huppert, F. A. (2009). Psychological Well-being: Evidence Regarding its Causes and Consequences. Applied psychology: Health and Wellbeing, 1(2), 137-164. doi: 10.1111/j.17580854.2009.01008.x

Hurst, J. L., \& Good, L. K. (2009). Generation y and career choice: the impact of retail career perceptions, expectations and entitlement perceptions. Career Development International, 14(6), 570-593.

Jabeen, F., Friesen, L., \& Ghoudi, K. (2018). quality of work life of emirati women and its influence on job satisfaction and turnover intention evidence from the uae. Journal of Organizational Change Management, 31(2), 352-370. doi 10.1108/jocm-01-2017-0016.

Jobstreet Employer ID. (2016). Tingkat kebahagiaan karyawan di Indonesia dan 3 faktor utama yang membuat karyawan bahagia dalam pekerjaan. Diakses dari www HYPERLINK "http://www/".Jobstreet.co.id/en/cms/employer
Kara, D., Kim, H., Lee, G., \& Uysal, M. (2018). The moderating effects of gender and income between leadership and quality of work life (QWL). International Journal of Temporary Hospitality Management, 30(3), 1419-1435. doi: 10.1108/IJCHM-09-2016-0514

Kurniawati, C. E. (2018). Pengaruh quality of work life terhadap work engagement dan organizational citizenship behaviour pada perusahaan elektronik di Surabaya. Agora, 6(2), 1-6.

Lantu, D, Erich, P \& Augusman R H. (2007). Servant leadership. Yogyakarta: Gradien Books.

Liman, H., Yaphar, N. L., \& Widjaja, D. C. (2017). Analisa pengaruh servant leadership terhadap job performance karyawan hotel x surabaya. Jurnal Hospitality dan Manajemen Jasa, 5(1), $1-5$.

Mahmoudi, M T., Azar, M., \& Bahrani, R. (2019). The impact of organizational happiness on the working life quality; a case study among isfahan university's staff. Journal of Entrepreneurship and Management, 83), 255-265. doi 10.33945/SAMI/IJAHSS.2019.3.3.

Malvikawalia. (2016). quality of work life- a study on Markfed. Journal of International Academic Research for Multidisciplinary, 4(9), 71-90.

Mayer, D M., Bardes M \& Piccolo, R F. (2008). Do servant-leaders help satisfy follower needs? An organizational justice perspective. European Journal of Work And Organizational Psychology, 17(2), 180-197. doi 10.1080/13594320701743558.

Merdiaty, N., Aldrian, N., Runtu, D Y N. (2019). Role of servant leadership on quality of work life (QWL) and work conflict with adversity quotient as mediator. International Journal of Research In Business And Social Science, 8(6), 88-95. doi 10.20525/ijbrs.v8i6.523

Nafei, W. (2015). The role of job embeddedness on quality of work life and organizational citizenship behavior: a study on Menoufia University Hospitals. International Journal of Business and Management, 10(4). doi: 10.5539/jjbm.v10n4p215.

Nafei, W. (2016). The effect of organizational agility on quality of work life: a study on commercial banks in egypt. International Journal of Business and Management, 16(1).

Nawawi, H. (2012). Manajemen strategik organisasi non-profit bidang pemerintahan: dengan ilustrasi di bidang pendidikan. Yogyakarta: Gadjah Mada University Press.

Organ, DW (1988). Penyajian Kembali Hipotesis KepuasanKinerja. Jurnal Manajemen, 14(4), 547-57.

Priansa, D. J. (2014). Perencanaan \& pengembangan SDM. Bandung: Alfabeta.

Pruijt, H. (2003). Performance and quality of work life. Journal of Organizational Change Management, 13(4), 384-400. doi: 10.1108/09534810010339077

Purnaya, I. G. K. (2016). Manajemen sumber daya manusia. Yogyakarta: Andi.

Putri, D. P., Musadieq, M. A., \& Sulistyo, C. W. (2018). Pengaruh servant leadership dan organizational citizenship behaviour terhadap kinerja karyawan. Jurnal Administrasi Bisnis (JAB), $58(2), 1-10$

Recruitufi. (2015). Job hopping: The new norm. Diakses dari http://people- press.org/report/300/aportrait-of-generationnext pada 30 Januari 2020.

Ryff, C. D., \& Keyes, C.L. (1995). The structure of psychological well being revisited. Journal of Personality and Social 
Psychology, 719-727. doi: 10.1037/022-3514.69.4.719

Sahni, J. (2019). Role of quality of work life in determining employee engagement and organizational commitment in telecom industry. International Journal for Quality Research, 13(2), 285-300.

Santrock, J. W. (2017). Psikologi pendidikan. Edisi kedua. Jakarta: Kencana.

Strauss, W., \& Howe, N. (1991). Generations: the history of America's future, 1584 to 2069. New York: William Morrow and Company Inc.

Sugiyono. (2012). Metode penelitian kuantitatif kualitatif dan $r \& d$. Bandung: Alfabeta.

Sumathi, V., \& Velmurugan, D. R. (2017). quality of work life of employees in private companies with reference to coimbatore. International Journal of Multidisciplinary Research and Development, 4(5). 128-131.

Suryaratri, R. D., \& Abadi, M. A. (2018). Modal psikologis dan intensi job hopping pada pekerja generasi millenial. IkraithHumaniora, 2(2), 77-83.
Timossi, S. L., Pedroso, B., Francisco de, C. A., \& Pilatti, A. L. (2008) Evaluation of quality of work life: An adaptation from the Walton's QWL Model. Proceedings of XIV International Conference of Industrial Engineering and Operation Management. 1-17.

Wahyuningsing, N. (2016). Peranan quality of work life dalam peningkatan kinerja pegawai. Al- Amwal: Jurnal Ekonomi dan Perbankan Syari'ah, 6(2), 279-292. DOI: 10.24235/amwal.v6i2.259

Walton, R.E. (1975). Criteria for quality of working life. In l.e. davis, a. b. cherns and associates (eds.) The quality of working. New York: The Free Press

Winarsunu, T. (2017). Statistik dalam penelitian psikologi dan pendidikan. Malang: UMM Press. 